\title{
Absence of bacterially induced RELM $\beta$ reduces injury in the dextran sodium sulfate model of colitis
}

\author{
Laila D. McVay, ${ }^{1}$ Sue A. Keilbaugh, ${ }^{1}$ Tracie M.H. Wong, ${ }^{2}$ Sonja Kierstein, ${ }^{3}$ Marcus E. Shin, ${ }^{1}$ \\ Michael Lehrke, ${ }^{4}$ Martina I. Lefterova, ${ }^{4}$ D. Edward Shifflett, ${ }^{5}$ Sean L. Barnes, ${ }^{6}$ Fabio Cominelli, ${ }^{6}$ \\ Steven M. Cohn, ${ }^{6}$ Gail Hecht,, ${ }^{5}$ Mitchell A. Lazar, ${ }^{4}$ Angela Haczku, ${ }^{3}$ and Gary D. Wu1 \\ ${ }^{1}$ Division of Gastroenterology, University of Pennsylvania School of Medicine, Philadelphia, Pennsylvania, USA. 'Division of Gastroenterology, \\ Hepatology and Nutrition, The Children's Hospital of Philadelphia, Philadelphia, Pennsylvania, USA. ${ }^{3}$ Division of Pulmonary Allergy and Critical Care and \\ ${ }^{4}$ Division of Endocrinology, Diabetes, and Metabolism, University of Pennsylvania School of Medicine, Philadelphia, Pennsylvania, USA. \\ ${ }^{5}$ Department of Medicine, Section of Digestive Diseases and Nutrition, University of Illinois at Chicago, Chicago, Illinois, USA. \\ ${ }^{6}$ Digestive Health Center of Excellence, University of Virginia Health Sciences Center, Charlottesville, Virginia, USA.
}

\begin{abstract}
Although inflammatory bowel disease (IBD) is the result of a dysregulated immune response to commensal gut bacteria in genetically predisposed individuals, the mechanism(s) by which bacteria lead to the development of IBD are unknown. Interestingly, deletion of intestinal goblet cells protects against intestinal injury, suggesting that this epithelial cell lineage may produce molecules that exacerbate IBD. We previously reported that resistin-like molecule $\beta$ (RELM $\beta$; also known as FIZZ2) is an intestinal goblet cell-specific protein that is induced upon bacterial colonization whereupon it is expressed in the ileum and colon, regions of the gut most often involved in IBD. Herein, we show that disruption of this gene reduces the severity of colitis in the dextran sodium sulfate (DSS) model of murine colonic injury. Although RELM $\beta$ does not alter colonic epithelial proliferation or barrier function, we show that recombinant protein activates macrophages to produce TNF- $\alpha$ both in vitro and in vivo. RELM $\beta$ expression is also strongly induced in the terminal ileum of the SAMP1/Fc model of IBD. These results suggest a model whereby the loss of epithelial barrier function by DSS results in the activation of the innate mucosal response by RELM $\beta$ located in the lumen, supporting the hypothesis that this protein is a link among goblet cells, commensal bacteria, and the pathogenesis of IBD.
\end{abstract}

\section{Introduction}

Members of the RELM/FIZZ protein family, which includes resistin, and RELM $\alpha,-\beta$, and $-\gamma$, are characterized by a signature carboxyl terminus sequence containing 10 completely conserved cysteine residues with invariant spacing (1). Each family member has a distinct pattern of tissue expression. Although they are best characterized as regulators of glucose homeostasis (2), more recent studies have suggested that one member of this protein family, resistin, may have proinflammatory properties. Recombinant resistin can activate proinflammatory cytokine expression in peripheral blood mononuclear cells (3), activate macrophages in vitro (4), and induce arthritis when injected into mice (3). Furthermore, serum levels of resistin are elevated in patients with both ulcerative colitis and Crohn disease (5). We have shown that RELM $\beta$ is produced specifically by intestinal goblet cells and is secreted apically into the intestinal lumen, where it exists intact in the stool of both mice and humans (6), and likely plays a role in the defense against parasitic nematode infections of the intestine (7). RELM $\beta$ expression is essentially undetectable in the colon of both germ-free immunocompetent and SCID mice but can be induced within 48 hours upon transfer to a conventional environment, demonstrating that the expression of this gene is dependent upon bacterial colonization of the gut (6). The other 2 RELM isoforms, $\alpha$ and $\gamma$, as well as

Nonstandard abbreviations used: DAI, disease activity index; DSS, dextran sodium sulfate; IBD, inflammatory bowel disease.

Conflict of interest: The authors have declared that no conflict of interest exists. Citation for this article: J. Clin. Invest. 116:2914-2923 (2006). doi:10.1172/JCI28121. resistin, are not induced in the colon by colonization of the intestine with commensal bacteria (8). In contrast to the constitutive expression of RELM $\beta$ in the colon of conventionally housed mice and low but detectable expression in the terminal ileum, expression of this gene is absent in the rest of the gastrointestinal tract, namely the small intestine and stomach (1).

There is compelling evidence for the role of commensal gut bacteria as a central factor in the pathogenesis of IBD. First, intestinal disease activity in animal models of IBD is ameliorated when they are housed in a germ-free environment $(9,10)$. Second, IBD afflicts regions of the intestinal tract most heavily colonized with gut bacteria $(11,12)$, and antibiotics have efficacy in treating Crohn disease $(11,13)$. Finally, the identification of NOD2/CARD15 as an IBD susceptibility gene provides a genetic link among innate immunity, bacteria, and the pathogenesis of $\operatorname{IBD}(14,15)$. As the interface between the bacteria-laden intestinal lumen and the mucosal immune system, the intestinal epithelium has been hypothesized to play a critical role in the development of IBD. Indeed, the ablation of goblet cells in the colon reduces the development of colitis in mice (16), suggesting that this cell lineage may be of particular relevance to the pathogenesis of IBD.

The observations that RELM $\beta$ protein expression is goblet cell specific and is expressed in those regions of the gut with the highest concentrations of commensal bacteria (12) and the highest frequency of involvement in patients with IBD (11) led us to determine whether RELM $\beta$ plays a role in the pathogenesis of intestinal inflammation in murine models of IBD. Herein, we show that RELM $\beta$ is an activator of the innate immune response and 
A
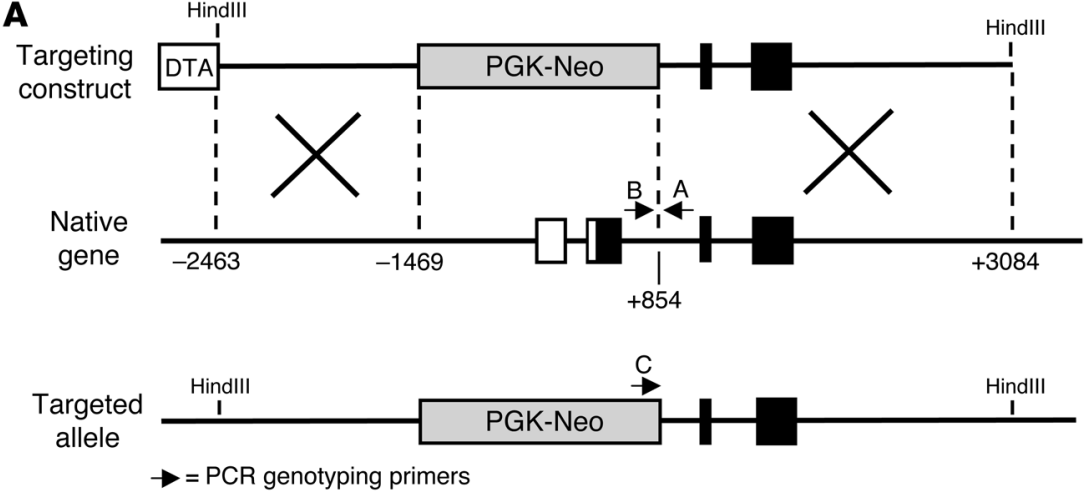

B

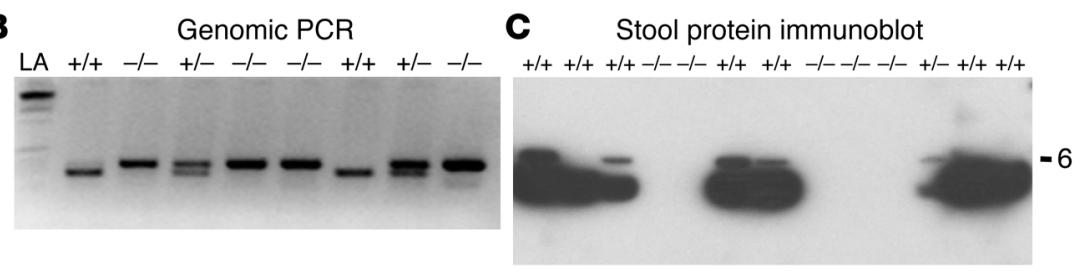

D

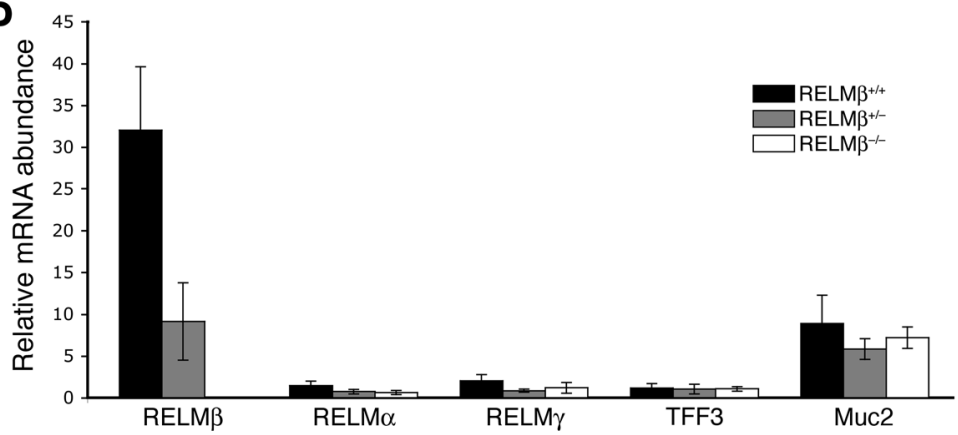

\section{Figure 1}

Characterization of the RELM $\beta$ knockout. (A) Schematic diagram of the knockout strategy. The phosphoglycerate kinase-Neo (PGK-Neo) cassette was used to disrupt 2323 bp of the RELM $\beta$ gene locus, replacing the promoter region and the first 2 exons. (B) Genomic PCR using primers shown in A. Amplification of a 295-bp product by primers $A$ and $B$ indicate the wild-type allele (lower band), whereas a 413-bp product amplified by primers $A$ and $C$ indicates the null allele (upper band). LA, ladder. (C) Immunoblot of RELM $\beta$ using protein isolated from the stool of wild-type and RELM $\beta$-knockout mice. (D) Quantification of mRNA expression for RELM isoforms and goblet cell-specific genes using RNA isolated from the proximal colon of RELM $\beta^{+/+}$, RELM $\beta{ }^{+/}$, and $\operatorname{RELM} \beta^{-/}$mice $(n=3$; mean $\pm \mathrm{SD})$. that disruption of this gene protects against dextran sodium sulfate-induced (DSS-induced) colitis in mice. These results provide a potential explanation for the results described by Itoh et al. (16) showing that mice with a reduction in colonic goblet cells are protected from DSS-induced colitis.

\section{Results}

Development and initial characterization of the RELM knockout. In order to determine the function of RELM $\beta$ in vivo, we utilized gene targeting to disrupt the locus for this gene and develop a RELM $\beta^{-/-}$ mouse (Figure 1, A and B). The RELM $\beta$-null allele was inherited in the appropriate Mendelian pattern. RELM $\beta^{-/-}$mice did not express detectable levels of either mRNA or protein for this gene, whereas RELM $\beta^{+/-}$mice exhibited a gene dosage-dependent decrease in RELM $\beta$ mRNA expression (Figure $1, C$ and D). RELM $\beta^{-/-}$mice developed normally and bred well, without obvious gross phenotype. Furthermore, there was no alteration in the mRNA expression of the other RELM isoforms or goblet cell-specific genes such as mucin 2 (Muc2) and trefoil factor 3 (Tff3) in the proximal colon of RELM $\beta^{-/-}$mice (Figure 1D). Similar findings were observed in both the cecum and distal colon (data not shown).

$R E L M \beta^{-/-}$mice are protected from DSS-induced colitis. In light of the central role that commensal bacteria play in the development of IBD in both mice and humans, together with the innate immunedependent activation of RELM $\beta$ protein expression in the intestine, we sought to determine whether intestinal inflammation would be altered in RELM $\beta^{-/-}$mice by inducing colitis using DSS (17). Four-percent DSS was delivered in drinking water for 8 days to age- and sex-matched RELM $\beta^{-/-}$mice and their wild-type littermates. To quantify clinical parameters of disease activity, we documented, on a daily basis, throughout the course of this study, all 3 components of a previously described disease activity index (DAI) (18): weight loss, intestinal bleeding, and stool consistency. The results, presented in Figure 2, are representative of 3 independent experiments. RELM $\beta^{-/-}$mice lost considerably less weight than the wild-type controls commencing on day 4 . The greater body weight of RELM $\beta^{-/-}$mice relative to controls was sustained throughout duration of the study (Figure 2A). In addition, the onset of intestinal bleeding and the development of loose stool were also significantly delayed in RELM $\beta^{-/-}$mice compared with their wild-type littermates (Figure 2B). At day 7 of this study, the overall DAI was significantly less for RELM $\beta^{-/-}$mice compared with wild-type mice $(3.29 \pm 0.12$ versus $3.63 \pm 0.09 ; P<0.05)$. Importantly, survival after DSS administration was dramatically enhanced in RELM $\beta^{-/-}$mice (Figure 2C). Consistent with the evidence for reduced injury, the percentage of the colonic mucosa containing ulcerations (Figure 2D) and the mRNA expression of an important mediator of inflammation in both patients with IBD and mice with DSSinduced colitis, TNF- $\alpha(19,20)$, were significantly reduced in RELM $\beta^{-/-}$mice (Figure $2 \mathrm{E}$ ). Taken together, these results provide compelling clinical evidence that RELM $\beta^{-/-}$mice are significantly less susceptible to DSS-induced colitis. 

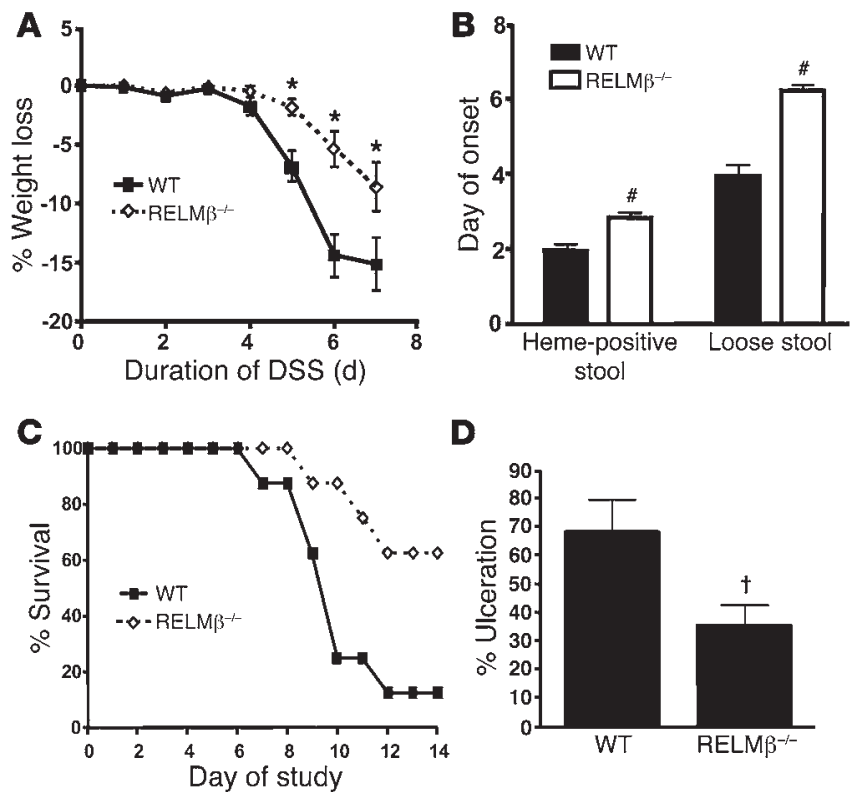

D

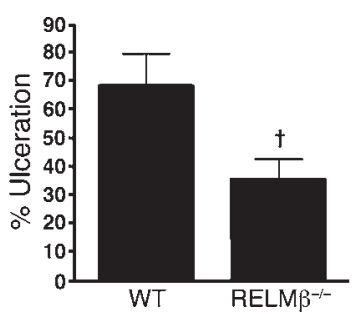

E
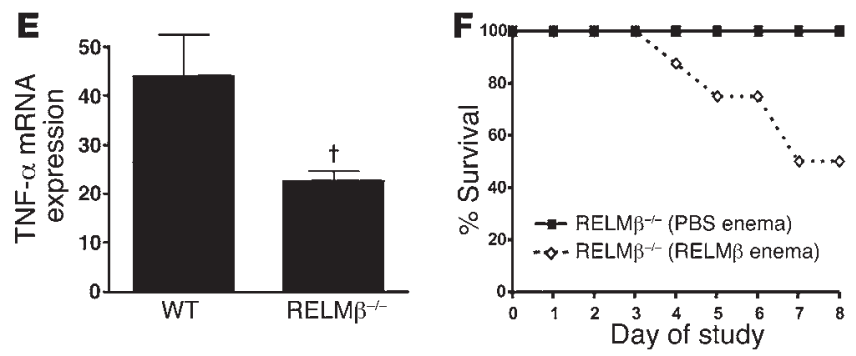

In order to determine the specificity with which RELM $\beta$ exerts its proinflammatory effects in DSS-induced colitis, we examined the effect of RELM $\beta$, administered by enema twice daily, on the development of DSS-induced colitis in RELM $\beta^{-/-}$mice. Reintroduction of RELM $\beta$ into the knockout mice resulted in a $50 \%$ mortality rate within 1 week of DSS administration, whereas all RELM $\beta^{-/-}$mice receiving the vehicle as an enema survived (Figure $2 \mathrm{~F}$ ). Because the administration of enemas altered stool consistency and may have contributed to the development of Hemoccult-positive (Beckman Coulter) stool, we were unable to determine DAI in these mice. However, even with the exclusion of the RELM $\beta$-treated mice that died early in the study, there was a trend toward an increase in percent body weight loss observed in the RELM $\beta$-treated mice compared with controls at the termination of the study $(14.34 \% \pm 2.35 \%$ versus $12.78 \% \pm 1.46 \%$ ).

Histologically, there was no difference in morphology of the colonic mucosa, including the number of goblet cells or the size of their granules, in wild-type versus RELM $\beta^{-/-}$mice (Figure 3, A

\section{Figure 3}

Preservation of colonic crypt cell proliferation, architecture, and goblet cells in RELM $\beta^{-/-}$mice treated with DSS. RELM $\beta$ immunostaining in the colon of wild-type (A) and RELM $\beta^{-/}$mice (B) (magnification, $\times 200)$. (C-F) Representative photomicrographs of "Swiss-rolled" colonic tissue obtained after 7 days of $4 \%$ DSS administration. H\&Estained sections of wild-type (C) and RELM $\beta^{-/-}$colons (D) (magnification, $\times 100)$. Alcian blue-stained sections of wild-type $(E)$ and RELM $\beta^{-1-}$ colons $(\mathbf{F})$ (magnification, $\times 100$ ).

\section{Figure 2}

Clinical evidence that RELM $\beta$ exacerbates DSS-induced colitis. (A) Daily percent weight loss of wild-type and RELM $\beta^{-/-}$mice treated with $4 \%$ DSS $\left(n=8\right.$ per group; mean \pm SEM; $\left.{ }^{*} P<0.01\right)$. (B) Mean time (days) to onset of intestinal bleeding (hemoccult positivity) and loose stools in wild-type and RELM $\beta^{-/-}$mice treated with $4 \%$ DSS $(n=8$ per group; mean \pm SEM; ${ }^{\#} P<0.05$ ). (C) Percent survival of wild-type and RELM $\beta^{-/}$mice treated with $4 \%$ DSS for 7 days ( $n=8$ per group). (D) Percentage of the colonic mucosa ulcerated in DSS-induced colitis in wild-type and RELM $\beta^{-1}$ mice treated with $4 \%$ DSS for 7 days $\left({ }^{\dagger} P<0.05\right)$. (E) Quantification of TNF- $\alpha$ mRNA expression in the colon of wild-type and RELM $\beta^{-1-}$ mice treated with $4 \%$ DSS for 7 days assessed by Northern blot normalized to 18S RNA ( $\left.{ }^{\dagger} P<0.05\right)$. (F) Percent survival of RELM $\beta^{-1-}$ mice treated with $4 \%$ DSS that received enemas twice daily with either vehicle (PBS) or recombinant murine $\operatorname{RELM} \beta(2 \mu \mathrm{g} / \mathrm{ml})$ ( $n=8$ per group).

and B). By contrast, upon treatment with DSS, analysis of colonic tissue obtained from wild-type mice revealed severe inflammation of the colon, with near complete loss of the colonic crypts and epithelium (Figure 3, C and E). By contrast, analysis of colonic tissue obtained from DSS-treated RELM $\beta^{-/-}$mice revealed the preservation of colonic crypt structures containing isolated goblet cells despite the presence of an intense inflammatory infiltrate (Figure 3 , D and F). The dilated crypt structures lined with isolated goblet cells suggest that, in the absence of RELM $\beta$, the colonic epithelium and its associated crypt structures may either be better able to survive destruction or may be more rapidly reconstituted in the setting of intestinal inflammation. Although recent evidence that RELM $\beta$ acts as a mitogenic factor in lung epithelium via a PI3Kdependent mechanism might be consistent with this notion (21), there was no difference in epithelial apoptosis, which was very rare, as determined by TUNEL staining, in both wild-type and RELM $\beta^{-/-}$mice that received DSS (data not shown). Alternatively, the RELM $\beta$-null mice may be more resistant to the initiation of disease induced by DSS.
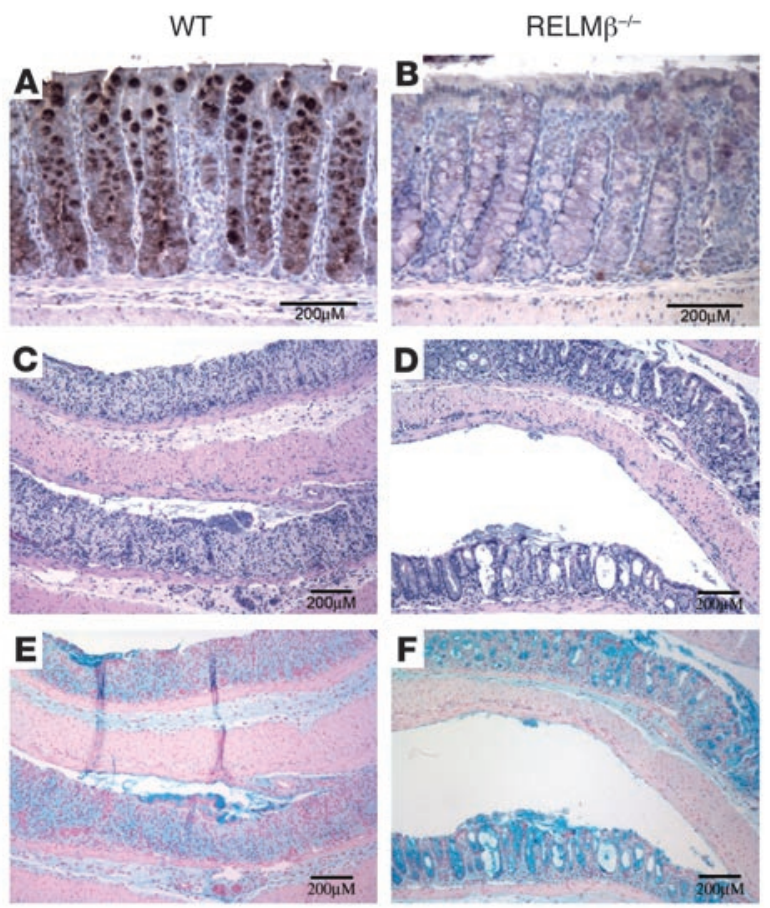


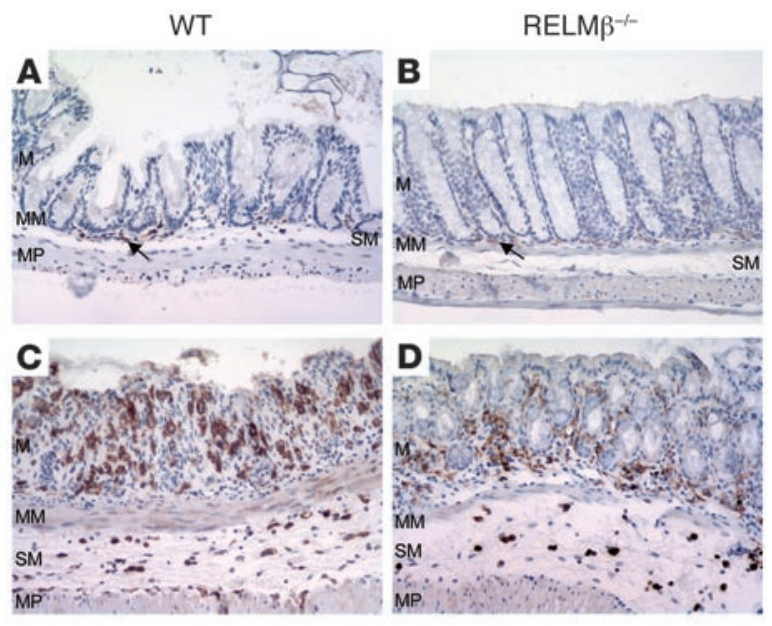

In order to more thoroughly characterize the inflammatory process in the wild-type and RELM $\beta^{-/-}$mice treated with DSS, the leukocyte components of the inflammatory infiltrate were determined histologically in a time-course study. After 2 days of DSS administration, the histologic appearance of both the wildtype and RELM $\beta^{-/-}$mice appeared normal, with only occasional F4/80-positive macrophages identified adjacent to the base of the colonic crypts (Figure 4, A and B). This was similar to the histologic appearance observed in untreated wild-type controls (data not shown). By contrast, the distal colons of both the wild-type and RELM $\beta^{-/-}$mice demonstrated an inflammatory infiltrate after 7 days of DSS administration that was significantly less pronounced in the RELM $\beta^{-/-}$than the wild-type mice (Figure 4, C and D, and Table 1), consistent with the evidence of less disease (Figure 2) and the preservation of colonic crypt structures in the RELM $\beta^{-/-}$mice (Figure 3). Importantly, a significant proportion of the leukocytic infiltrate in both the wild-type and RELM $\beta^{-/}$mice (approximately $30 \%$ ) consisted of F4/80-positive macrophages (Figure 4, C and D, and Table 1). By contrast, granulocytes were responsible for only a small component of the inflammatory infiltrate in both the wildtype and RELM $\beta^{-/-}$mice (Table 1 ). In total, these results are consistent with previous notions that DSS-induced colitis is primarily an acute innate immune model in which macrophages may play a predominant role (22). Since the total inflammatory infiltrate was reduced in the RELM $\beta^{-/-}$mice without any alteration in the proportion of either macrophages or granulocytes, these results are consistent with a role for RELM $\beta$ as a more general upstream modifier of disease activity rather than a chemoattractant for a specific innate immune cell type.

Epithelial function in response to $D S S$ is not altered in RELM $\beta^{-/-}$mice. In order to determine whether RELM $\beta$ exacerbates colitis by modifying early events associated with the initiation of DSS-induced colitis, we examined 2 parameters of colonic epithelial function in the RELM $\beta^{-/-}$mice, cell proliferation and barrier function. Colonic crypt cell proliferation was determined by immunohistochemical detection of Ki-67 in colonic tissue

\section{Figure 4}

Analysis of the inflammatory cell infiltrate in DSS-induced colitis of wild-type and $R E L M \beta^{-/-}$mice. F4/80 staining in the colon wild-type mice (A) or RELM $\beta^{---}$mice (B) treated with $4 \%$ DSS for 2 days (magnification, $\times 200$ ). Arrows indicate F4/80-positive macrophages at the based of colonic crypts. F4/80 staining in the colon of wild-type mice (C) or RELM $\beta^{--}$mice (D) treated with $4 \%$ DSS for 7 days (magnification, ×200). M, mucosa; MM, muscularis mucosa; SM, submucosa; $\mathrm{MP}$, muscularis propria. sections from both wild-type and RELM $\beta^{-/-}$given 4\% DSS for 2 days. Although the histologic appearance of the colonic mucosa was normal in both groups of mice, crypt cell proliferation was virtually absent in the distal colon of both wild-type (data not shown) and RELM $\beta^{-/-}$mice (Figure 5A). Importantly, Ki-67 staining of the proximal colon and cecum of both wild-type and RELM $\beta-/$ mice, where colitis does not develop after longer-term treatment with DSS, was not different from that seen in these gut segments obtained from untreated mice. In order to determine whether RELM $\beta$ expression alters colonic epithelial function in response to DSS treatment, prior to the onset of inflammation, we assessed epithelial barrier function in the distal colon of both wild-type and $\mathrm{RELM} \beta^{-/-}$mice treated with $4 \%$ DSS for 2 days. Alterations in intestinal epithelial barrier function have been hypothesized to play an important role in the pathogenesis of IBD (23). Barrier function was equally reduced in the distal colon of both wild-type and RELM $\beta^{-/-}$mice, as demonstrated by a decrease in transepithelial resistance (TER) (Figure 5B) and a corresponding increase in short-circuit current (data not shown). To determine whether RELM $\beta$ can directly activate a proinflammatory response in the intestinal epithelium, we examined the effect of recombinant RELM $\beta$ on the inflammatory response of an intestinal cell line, LS174T, in vitro. A dose-ranging study of RELM $\beta$ from 0.1 to 1.0 $\mu \mathrm{g} / \mathrm{ml}$ failed to induce the expression of IL-8 mRNA expression or activate the IL-8 promoter, an NF-кB-dependent gene, in reporter gene studies (data not shown). Together, these results demonstrate that RELM $\beta$ does not have a primary effect on the colonic epithelium associated with the initiation of DSS-induced colitis.
Table 1

Quantification of leukocyte populations in DSS-induced colitis

\begin{tabular}{lclcc}
\hline & Wild-type & Wild-type & RELM $\beta^{-/-}$ & RELM $\beta^{-/-}$ \\
& (DSS, 2 d) & (DSS, 7 d) & (DSS, 2 d) & (DSS, 7 d) \\
Total leukocytes/HPF & $145 \pm 14.4$ & $458 \pm 60.0$ & $128 \pm 13.5$ & $250 \pm 31.0^{\mathrm{A}}$ \\
Macrophages/HPF & $25 \pm 2.0(17 \%)$ & $136 \pm 18.1(30 \%)$ & $32 \pm 2.4(25 \%)$ & $74 \pm 11.3^{\mathrm{A}}(29 \%)$ \\
Granulocytes/HPF & $4 \pm 0(3 \%)$ & $16 \pm 2.6(4 \%)$ & $6 \pm 2.1(5 \%)$ & $8 \pm 1.5^{\mathrm{A}}(3 \%)$ \\
\hline
\end{tabular}

Cells counted in H\&E- and F4/80-stained distal colonic tissue sections using 3 random $\times 600$-magnification fields for each of 4 mice of each genotype treated with $4 \%$ DSvS for the times periods indicated (mean \pm SEM; numbers in parentheses indicate percentage of total leukocyte count; ${ }^{A} P<0.03$ relative to wild-type). HPF, high-power field. 
A

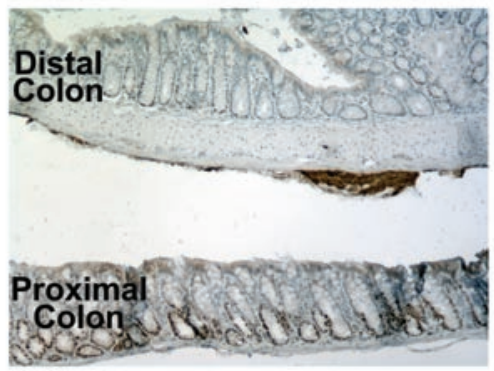

B

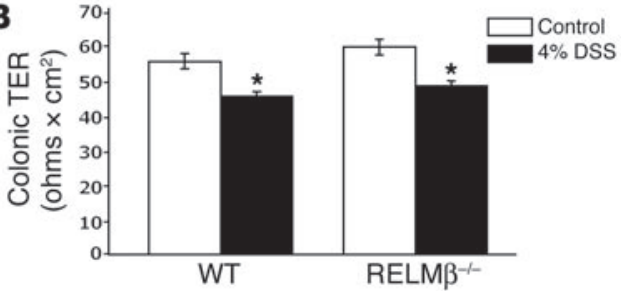

Figure 5

Short-term DSS treatment inhibits colonic crypt cell proliferation and reduces barrier function in $R E L M \beta^{-/-}$mice in the absence of gross inflammation. (A) Ki-67 staining of a Swiss-rolled colon isolated from a RELM $\beta^{-/-}$mouse after treatment with $4 \%$ DSS for 2 days (magnification, $\times 100$ ). (B) Assessment of epithelial barrier function through the measurement of transepithelial resistance (TER) in wild-type and $\mathrm{RELM} \beta^{-/-}$mice with and without $4 \%$ DSS for 2 days. ${ }^{*} P \leq 0.01$.

RELM $\beta$ activates innate immune responses both in vitro and in vivo. Upon disruption of colonic epithelial barrier function, it is possible that RELM $\beta$ located in the lumen may augment the inflammatory response by activating leukocytes that normally reside in the lamina propria of the intestinal mucosa. Macrophages have been suggested to be a primary innate immune cell type that is activated upon the loss of epithelial barrier function in DSS-induced colitis (22). Indeed, immunohistochemical staining for F4/80 revealed that macrophages are a predominant cell type associated with DSSinduced colitis in both wild-type and RELM $\beta^{-/-}$mice (Figure 4 and Table 1). To determine whether RELM $\beta$ could activate macrophages in vitro, a multiplex assessment of protein secretion induced by the treatment of thioglycolate-isolated macrophages with recombinant RELM $\beta$ revealed the specific induction of only 2 proteins, TNF- $\alpha$ and IL-15 (Figure 6A), out of 22 cytokines and chemokines assayed (IL-1 $\alpha$, IL-1 $\beta$, IL-2, IL-4, IL-5, IL-6, IL-7, IL-9, IL-10, IL-12p70, IL-13, IL-17, G-CSF, GM-CSF, IFN- $\gamma$, IP-10, KC, MCP-1, MIP-1 $\alpha$, and RANTES). Interestingly, both TNF- $\alpha$ and IL-15 have been previously shown to play an important role in DSS-induced colitis $(20,24)$. Although TNF- $\alpha$ levels were reduced in RELM $\beta^{-/-}$compared with wild-type mice treated with DSS (Figure 2E), there was no difference in the mRNA expression of IL-15 (data not shown). A doseranging study revealed that isolated macrophages secrete high levels of TNF- $\alpha$ in response to recombinant RELM $\beta$ at a low microgram per milliliter concentration (Figure 6B). The maximal secretion of TNF- $\alpha$ occurred rapidly, within 3 hours of stimulation (data not shown).

To determine the effect of RELM $\beta$ on the immune system in vivo, recombinant RELM $\beta$ was injected i.p. into mice, and peritoneal cells were collected for gene expression studies as well as assessment of the cellular profile. Quan- titative assessment of the innate immune cellular profile in the peritoneal lavage fluid by cytospin analysis showed that RELM $\beta$ induced a significant, time-dependent influx of neutrophils (Figure 7A). The peak neutrophil influx occurred 24 hours after the injection of RELM $\beta$ ( $P=0.005$ compared with vehicle-treated controls). There was also an increase in the level of eosinophils, but this change did not reach statistical significance when compared with that in mice treated with vehicle control (data not shown). By contrast, the abundance of mast cells, which in the peritoneum was approximately $5 \%$ of that of macrophages, did not change with RELM $\beta$ administration. While injection of the vehicle, which consisted of PBS spiked with trace amounts of LPS equivalent to that measured in the recombinant RELM $\beta$, also induced an increase in the number of infiltrating neutrophils (Figure 7A), this increase was not significantly different from that obtained by injection of PBS alone (data not shown). While the underlying mechanism for the peritoneal neutrophil influx is unclear, we found that 1 hour after RELM $\beta$ injection, there was a significant increase in mRNA expression of TNF- $\alpha$, a cytokine responsible for initiation of proinflammatory changes, as measured by quantitative RT-PCR (Figure 7B). Interestingly, RELM $\beta$ injection also caused morphologic changes characteristic of macrophage activation, including enlargement and foamy transformation of the cytoplasm, which was most apparent after 48 hours (Figure 7C). FACS analysis of the $\mathrm{F} 4 / 80$-positive cell population revealed that the proportion of these cells did not change significantly, upon injection of RELM $\beta$, relative to the total cell population (Figure 7D). There was, however, a striking increase in the amount of TNF- $\alpha$-producing cells within this macrophage population (28\% of TNF- $\alpha$-positive cells in the F4/80-positive population) when compared with that in vehicle-treated mice $(7 \% ; P=0.011)$ (Figure $7, \mathrm{E}$ and $\mathrm{F})$. These data together with the morphological changes suggest that RELM $\beta$ is an immune activator of macrophages in vivo. In contrast, no activation was apparent in the other mononuclear cell populations following RELM $\beta$ treatment, as we observed no increase in the proportion of B220-positive B cells, CD3-positive T cells, the CD4or CD8-positive $\mathrm{T}$ cell subclasses or their expression of the IL-2 receptor, CD25 (Table 2). Thus, recombinant RELM $\beta$ activated the production of the proinflammatory cytokine TNF- $\alpha$ by macrophages and induced inflammatory cell infiltration when injected locally. The ability of RELM $\beta$ to activate the expression of TNF- $\alpha$, an upstream mediator of the general inflammatory response, is
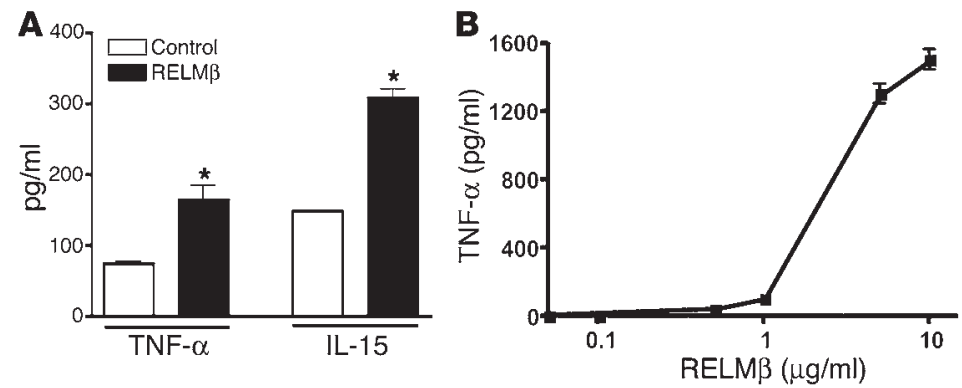

Figure 6

Recombinant RELM $\beta$ is an activator of macrophages in vitro. (A) Recombinant RELM $\beta$ activates TNF- $\alpha$ and IL-15 protein expression in thioglycolateisolated macrophages $\left({ }^{*} P<0.01\right)$. (B) Dose-dependent induction of TNF- $\alpha$ protein expression in thioglycolate-isolated macrophages treated with recombinant murine RELM $\beta$. 

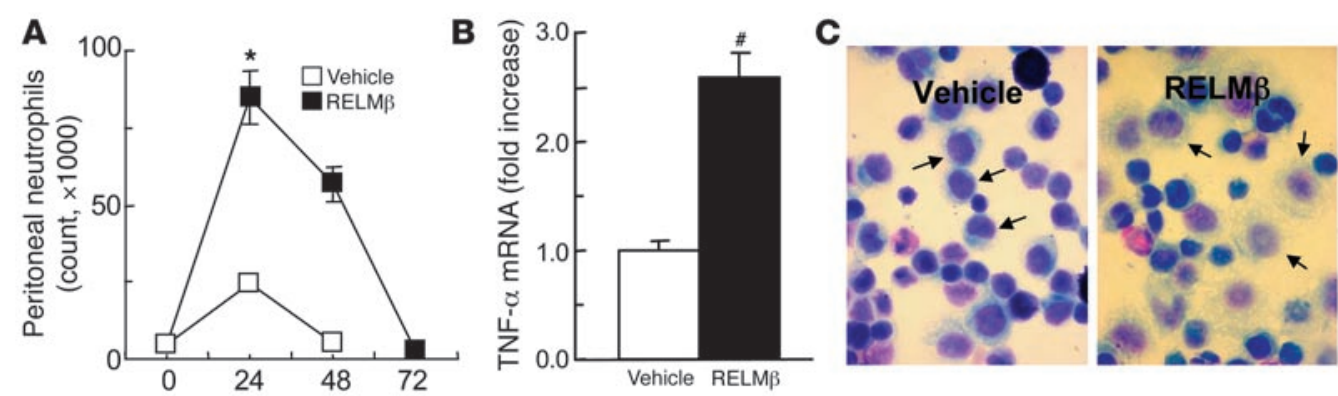

Time after RELM $\beta$ injection (h)
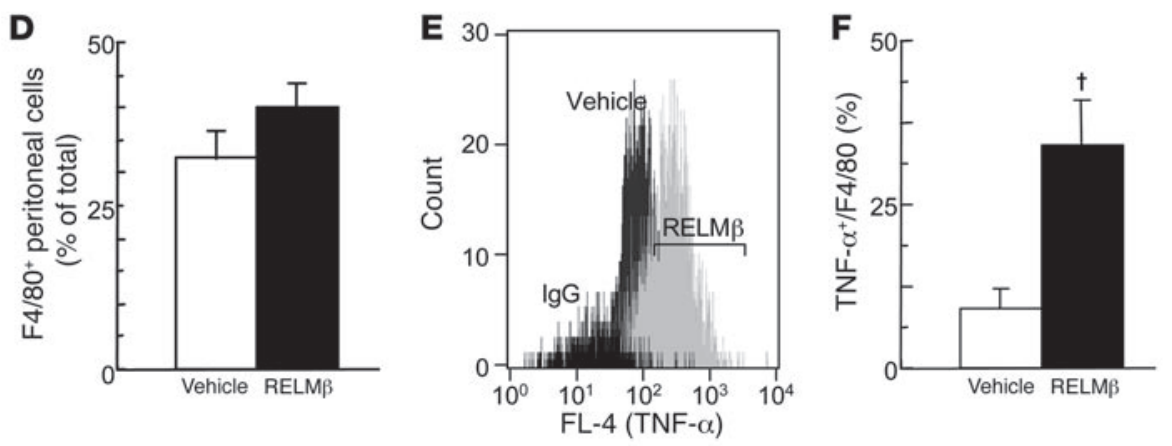

\section{Figure 7}

Intraperitoneal injection of RELM $\beta$ induces a proinflammatory response. (A) Time course of neutrophil influx (mean \pm SEM of $n=4-8$ mice; $\left.{ }^{*} P=0.005\right)$ in isolated peritoneal cells after vehicle or RELM $\beta$ injection. (B) Quantification of TNF- $\alpha$ mRNA expression in isolated peritoneal cells by RT-PCR 1 hour after vehicle or RELM $\beta$ injection $\left(n=4\right.$; mean \pm SEM; $\left.{ }^{P} P=0.041\right)$. (C) Peritoneal macrophages (arrows) show enlargement and foamy transformation of the cytoplasm 48 hours after i.p. RELM $\beta$ injection (magnification, $\times 1,000$ ). (D) Quantification of F4/80-positive macrophages by FACS $(n=4$; mean \pm SEM). (E) Representative overlay histograms of TNF- $\alpha$ expression in F4/80-positive cells from vehicle or RELM $\beta$-treated mice. (F) Quantification of intracellular TNF- $\alpha$ expression in F4/80-positive macrophages 48 hours after i.p. RELM $\beta$ injection (mean \pm SEM of $n=5$ mice; ${ }^{\dagger} P=0.011$ ).

consistent with the previously defined role of macrophages and TNF- $\alpha$ in DSS-induced colitis $(20,22)$. This ability also correlates well with the general decrease in the inflammatory infiltrate observed in RELM $\beta^{-/-}$mice treated with DSS for 7 days compared with similarly treated wild-type mice (Figure 4 and Table 1).

$R E L M \beta$ expression is strongly induced in the terminal ileum of the $S A M P 1 / F c$ model of Crobn disease. Our results in DSS-induced colitis suggest that RELM $\beta$ may play a role in the exacerbation of intestinal inflammation in other more spontaneous, chronic, and immunologically based models of IBD such as that observed in SAMP1/FC mice. Although the AKR background strain of the SAMP1/Fc mice exhibits low levels of RELM $\beta$ expression in the terminal ileum (1) (Figure 8B), mRNA and protein expression was strongly induced in the ileum of SAMP1/Fc mice concurrent with the onset of inflammation and the development of goblet cell hyperplasia (Figure 8, A and C). Interestingly, IL-4, a Th2 cytokine, has recently been implicated as a critical mediator in the perpetuation of disease in SAMP1/Fc mice (25). We have also shown that Th2-mediated inflammatory responses, induced by intestinal parasites in an IL-4 receptor-dependent fashion, strongly activate the expression of RELM $\beta$ in the intestinal tract (7).

\section{Discussion}

Our results demonstrate that RELM $\beta^{-/-}$mice are protected from DSS-induced colitis. As an acute model of intestinal injury, the DSS-induced colitis model is ideal for assessing the role of RELM $\beta$ in the intestinal inflammatory response for several reasons. First, DSS-induced colitis can be ameliorated by treatment with anti- biotics used clinically in patients with IBD (11), which have also been shown to reduce RELM $\beta$ expression (26), demonstrating that commensal bacteria play a role in the development of inflammation in this model system (27). Second, as with the induction of RELM $\beta$ by bacterial colonization, DSS-induced colitis also develops in SCID mice, eliminating the role of adaptive immunity as a factor in this model (28). Finally, the ablation of goblet cells in the colon reduces mucosal damage in DSS-induced colitis (16).

In order to ascertain the mechanism by which RELM $\beta^{-/-}$mice are protected from DSS-induced colitis, we first focused on the effect of this protein on epithelial cell proliferation and barrier function. The initiating event by which DSS induces colitis appears to be a reduction in colonic crypt epithelial proliferation leading to the

\section{Table 2}

FACS analysis of peritoneal lymphocyte subpopulations 48 hours after vehicle or RELM $\beta$ injection

\begin{tabular}{|c|c|c|c|}
\hline Marker & Vehicle & RELM $\beta$ & $P$ value \\
\hline B220+/total (\%) & $85.5 \pm 9.0$ & $87.0 \pm 9.1$ & NS \\
\hline CD3+/total (\%) & $23.0 \pm 2.9$ & $26.2 \pm 2.5$ & NS \\
\hline $\mathrm{CD}^{+} / \mathrm{CD}^{+}(\%)$ & $73.7 \pm 1.1$ & $71.4 \pm 2.6$ & NS \\
\hline CD8+/CD3+ (\%) & $23.7 \pm 0.9$ & $22.8 \pm 2.1$ & NS \\
\hline $\mathrm{CD}^{25} 5^{+} \mathrm{CD} 4^{+}(\%)$ & $21.9 \pm 3.8$ & $14.4 \pm 2.8$ & NS \\
\hline $\mathrm{CD}^{25} / \mathrm{CD} 8^{+}(\%)$ & $1.7 \pm 0.6$ & $1.8 \pm 0.7$ & NS \\
\hline
\end{tabular}

Mean \pm SEM of $n=4$. 

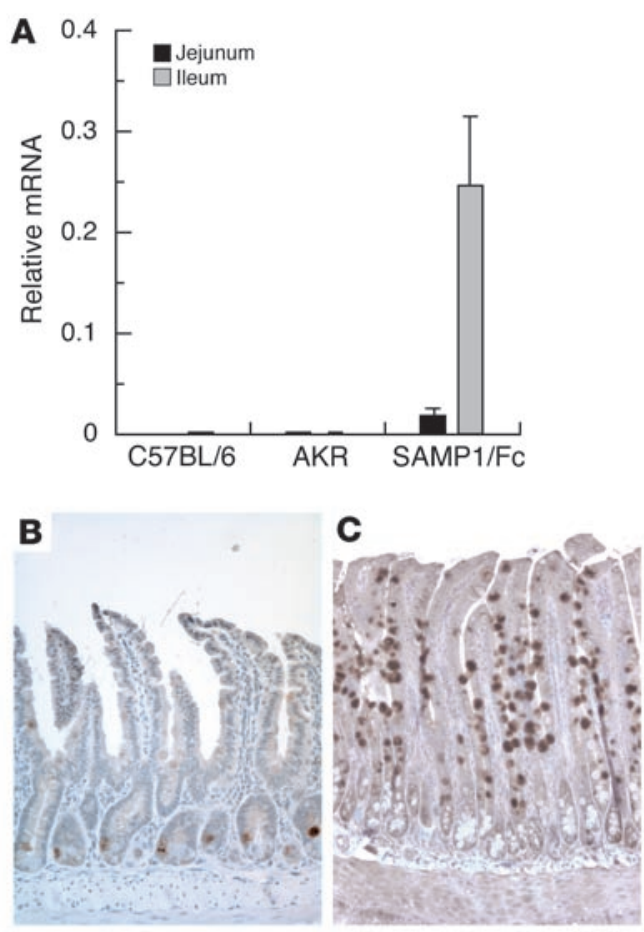

Figure 8

RELM $\beta$ expression is strongly activated in the terminal ileum of the SAMP1/Fc mice. (A) RELM $\beta$ mRNA levels were determined by quantitative real-time PCR in the jejunum and ileum of 40 -week-old C57BL/6, AKR, and SAMP1/Fc mice. 18S rRNA was used as an endogenous control. RELM $\beta$ mRNA levels are expressed as mean \pm SEM relative to $18 \mathrm{~S}$ rRNA $\left(\times 10^{-2}\right)$ ( $n=5$ per group). Immunohistochemical detection of RELM $\beta$ in the terminal ileum of AKR (B) and SAMP1/Fc mice (C) (magnification, $\times 200$ ).

loss of this progenitor cell compartment (29). Subsequent reduction of epithelial barrier function (30) may then allow antigenic lumenal contents to activate resident innate immune cell populations in the lamina propria, such as macrophages, resulting in colonic inflammation (22). Although RELM $\beta$ does not have any epithelial cell autonomous effects in the setting of DSS-induced colitis, our data suggest that RELM $\beta$ derived from the lumen, delivered to the lamina propria through a disrupted epithelial barrier, may activate immune cells to produce inflammatory mediators such as TNF- $\alpha$.

In mammals, TNF- $\alpha$ is secreted by macrophages, monocytes, neutrophils, NK cells, and T cells in response to proinflammatory changes in the local environment (31). In Figure 2E, we show that TNF- $\alpha$ expression is significantly lower in the DSS-induced colitis in RELM $\beta^{-/-}$mice compared with that induced in wild-type mice. Macrophages, which appear to be a prominent inflammatory cell type in DSS-induced colitis in both wild-type and RELM $\beta^{-/-}$mice (Figure 4 and Table 1), are therefore likely to be the principal source of TNF- $\alpha$. This suggests that RELM $\beta$ may regulate the expression of TNF- $\alpha$ in macrophages. Indeed, we show that in vitro treatment of thioglycolate-induced peritoneal macrophages with recombinant RELM $\beta$ stimulated the release of TNF- $\alpha$ protein (Figure 6) and that, in vivo, i.p. injection of RELM $\beta$ rapidly induced de novo TNF- $\alpha$ protein synthesis in F4/80-positive macrophages isolated from the peritoneum (Figure 7, E and F).
Together with the induction of morphologic changes in peritoneal macrophages consistent with an activated phenotype (Figure $7 \mathrm{C})$, the induction of TNF- $\alpha$ expression in macrophages demonstrates that RELM $\beta$ is capable of directly activating macrophages in vivo. Indeed, this is consistent with the ability of resistin, a closely related protein, to induce the expression of proinflammatory cytokines such as TNF- $\alpha$ in peripheral blood mononuclear cells (3) as well as macrophage cell lines (4).

Although our data implicate macrophages as the predominant immune cell type that is activated by RELM $\beta$, it is certainly possible that this protein may influence the biology of other immune and inflammatory cells present in the setting of DSS-induced colitis (Figure 4 and Table 1; and ref. 18). In this regard, we show in Figure 7A that i.p. injection of RELM $\beta$ leads to the influx of neutrophils into the peritoneum, a process that possibly influences the inflammatory changes induced by DSS, particularly during the initiation of colitis in this model.

Although the physiologic function of RELM $\beta$ has yet to be determined, like resistin (32), RELM $\beta$ seems to induce insulin resistance in vivo when either administered systemically or ectopically expressed $(33,34)$. There is growing evidence that insulin resistance, the hallmark of type 2 diabetes mellitus, is due in part to a state of chronic inflammation perpetuated by circulating inflammatory mediators such as TNF- $\alpha$ (35). Indeed, previous studies have reported that TNF- $\alpha$ inhibits insulin signaling by serine phosphorylation of IRS1 (36) and that the deletion of this gene or its receptors in mice prevents diet-induced insulin resistance (37). Most of these immune mediators are associated with an innate immune response in which macrophages may play an important role (35). In this regard, our results showing that RELM $\beta$ is an activator of macrophages leading to TNF- $\alpha$ production are consistent with the role that this molecule may play in host metabolism.

In Figure 6B, we provide results of a dose-response study of RELM $\beta$ on the induction of TNF- $\alpha$ protein expression in isolated peritoneal macrophages. The induction of TNF- $\alpha$ in this model occurs at higher levels of RELM $\beta$ protein than we have previously reported in the stool (7). It is possible that levels of RELM $\beta$ concentrated in the granules of goblet cells and released in proximity to inflammatory cells located in the lamina propria may be considerably greater than the steady-state levels of RELM $\beta$ in the stool. Furthermore, it must be noted that RELM $\beta$, like resistin, which is the prototypical member of this family, are highly cysteine-rich proteins (1). It is currently unknown whether the recombinant protein folds correctly, a process that may have an effect on the potency of its bioactivity. This is why we have utilized the RELM $\beta^{-/-}$ mouse to focus on the role of the endogenous RELM $\beta$ protein on the development of colitis in the DSS model.

The presence of resistin and RELM $\beta$ has been shown to correlate with the severity of inflammatory changes in patients with rheumatoid arthritis (3) and with intestinal bacterial overgrowth observed in CFTR-null mice (26), respectively. In fact, intraarticular injection of resistin into mice results in inflammatory infiltrate and pannus formation in the synovium (3). Taken together, our data and the results of these previously published studies support a proinflammatory function for RELM $\beta$. We speculate that this molecule may act by the rapid induction of TNF- $\alpha$ synthesis and release by macrophages followed by the subsequent recruitment of other inflammatory cells such as neutrophils (Figure 7A).

RELM $\beta$ is also associated with inflammation in a more chronic and immunologically mediated model of IBD, SAMP1/Fc mice 
(Figure 8). The pattern of inflammation in these mice is remarkably similar to that of Crohn disease in humans, with the spontaneous development of disease located primarily in the terminal ileum, and is characterized by discontinuous transmural inflammation with the formation of granulomas, the development of perirectal fistulas, and the amelioration of disease by the administration of TNF- $\alpha$-neutralizing monoclonal antibodies $(25,38)$. As occurs in DSS-induced colitis, and particularly relevant to patterns of RELM $\beta$ expression, the inflammatory response in these SAMP1/Fc mice is accelerated by gut bacteria (39). The strong induction of RELM $\beta$ in the terminal ileum of these mice concurrent with disease activity (Figure 8 ) together with the reduction in the severity of DSS-induced colitis in RELM $\beta^{-/-}$mice (Figure 2 ) and the ability of exogenous RELM $\beta$ to activate the innate immune response both in vitro and in vivo (Figures 6 and 7) provide compelling evidence for a role of RELM $\beta$ in modulating intestinal inflammation. The ability of RELM $\beta$ to activate the expression of TNF- $\alpha$ may be particularly relevant to human IBD given the therapeutic efficacy of anti-TNF- $\alpha$ biologics (19). Although our present studies clearly demonstrate a role for RELM $\beta$ in acute intestinal inflammation, breeding the RELM $\beta^{-/-}$genotype onto the SAMP1/Fc background will help to ascertain the role of RELM $\beta$ within the context of a more chronic disease process.

It is generally accepted that the goblet cell lineage plays an important role in maintaining mucosal integrity in the gut through the production of mucin and trefoil factors $(40,41)$. However, recent studies have questioned this because disruption of goblet cells reduces susceptibility of mice to colonic injury (16). Our results reconcile these seemingly disparate observations by showing that the absence of goblet cell RELM $\beta$ dramatically reduces susceptibility to DSS-induced colitis. In this regard, the characteristic depletion of goblet cell granules in the presence of active IBD (42) may actually be a protective compensatory mechanism. The ability of RELM $\beta$ to activate the innate immune response is consistent with the recently described crystal structure of both RELM $\beta$ and resistin, which reveals a multimeric complex with similarity to the $\mathrm{C} 1 \mathrm{q}$ complement protein and the TNF family of immune regulatory proteins $(43,44)$. The identification of RELM $\beta$ as a mediator of the mucosal inflammatory response emphasizes the importance of the goblet cell lineage in the innate response to commensal bacteria in the gut and the pathogenesis of IBD.

\section{Methods}

Generation of RELM $\beta$-knockout mice. The targeting strategy for the disruption of the endogenous RELM $\beta$ gene locus is depicted in Figure 1A. A $129 \mathrm{SvEv}$ BAC library was screened by PCR, and a 5547-bp HindIII fragment of the RELM $\beta$ gene locus was cloned into $\mathrm{pKS}^{-}$(Promega). The targeting vector, which contains phosphoglycerate kinase-Neo ${ }^{\mathrm{r}}\left(\mathrm{PGK}-\mathrm{Neo}^{\mathrm{r}}\right)$ and diphtheria toxin A (DTA) cassettes, was introduced into mouse ES stem cells (in Genious Targeting Laboratory Inc.) by electroporation, and the cells were subjected to selection under G418. Homologous recombinants, identified by genomic PCR and confirmed by Southern blotting, were then injected into blastocysts, and the resulting male chimeras were mated with female C57BL/6 mice. After germline transmission of the null allele was confirmed by genomic PCR and Southern blotting, $\mathrm{F}_{1}$ mice were then interbred to obtain mice on a mixed 129SVEV/C57BL6 background. Genomic PCR to genotype the resulting mice and identify wild-type, RELM $\beta^{+/-}$, and RELM $\beta^{-/-}$was performed using the following primers: A: 5'-TAGTGCAGGAGATCGTCTTA-3'; B: 5'-TCTGATGCCCTCTTCTGGCT-3'; C: 5'-TGGATGTGGAATGTGTGCGA-3'. A representative example of a genotyping PCR results is shown in Figure 1B.
SAMP1/Fc mice. These mice were maintained under specific pathogenfree conditions at the Animal Facility of the University of Virginia. AKR mice used as controls were purchased from The Jackson Laboratory. All experiments were approved by the Animal Care and Use Committee at the University of Virginia.

Immunoblots, immunohistochemistry, TUNEL staining, Northern blots, and quantitative RT-PCR. The methods used for the isolation of stool protein and immunoblot detection using a polyclonal rabbit anti-mouse antibody to mRELM $\beta$ and F4/80 (AbD Serotec) have been previously described (6). Sections for TUNEL staining were preincubated with Proteinase K Solution (Roche Diagnostics) for 15 minutes at room temperature followed by the use of the Apoptosis Detection Kit (Chemicon International) per the instructions of the manufacturer. Positive controls for TUNEL staining were generated by treating sections of normal mouse colon with RNasefree DNase I (Roche Diagnostics).

Colonic tissues from both wild-type and $\mathrm{RELM}^{-/-}$mice were divided lengthwise with one-half of the colon used for RNA isolation and the other one-half "Swiss rolled" with the distal colon in the center and fixed in $10 \%$ neutral buffered formalin for paraffin embedding. The method for isolation of RNA; primer sequences for RELM $\beta$, RELM $\alpha$, RELM $\gamma$, Muc2, and TFF3; as well as the conditions for quantitative RT-PCR have been previously described (6-8). The primer sequences utilized to quantify TNF- $\alpha$ expression in peritoneal lavage cells by RT-PCR were: forward, $5^{\prime}$ CAGACCCTCACACTCAGATCATCTT-3', and reverse, 5'-CCACTTGGTGGTTTGCTACGA-3'. Alcian blue, which stains mucopolysaccharides, was used to identify goblet cells. These sections were counterstained with nuclear fast red as previously described (45).

IL-8 expression was quantified using RNA isolated from LS174T cells treated for 24 hours with $0.1,0.5$, or $1.0 \mu \mathrm{g} / \mathrm{ml}$ hRELM $\beta$. Quantification of mRNA expression of IL-8, normalized to GAPDH levels, was performed on an ABI Prism 7000 Sequence Detection System (Applied Biosystems) using SYBR Green as the fluorescent probe. The oligonucleotide primer sequences used for human IL-8 were: forward, $5^{\prime}$-GTGCTAAAGAACTTAGATGTCAGTGCATA- $3^{\prime}$, and reverse, $5^{\prime}$-TGGTCCACTTCTCAATCACTCTCA- $3^{\prime}$.

For the TNF- $\alpha$ and IL-15 quantification by Northern blotting, total RNA $(10 \mu \mathrm{g})$ for each sample was electrophoretically separated, transferred to a nylon membrane, and UV cross-linked. After imaging the membrane using a Bio-Rad ChemiDoc system, the blot was hybridized to a PCR fragment of either murine TNF- $\alpha$ (forward, 5'-AGGGGCCACCACGCTCTTCTGT-3'; reverse, $5^{\prime}$-GCAAATCGGCTGACGGTGTGG-3') or murine IL-15 (forward, 5'-TCTCGTGCTACTTGTGTTTCCTTC-3'; reverse, 5'-GTTTTCTCCTCCAGCTCCTCACAT-3'). The PCR fragments were isolated from agarose gels, radioactively labeled using Megaprime DNA Labeling Systems (Amersham Biosciences), and isolated from unincorporated nucleotides by NICK columns (Amersham Biosciences). Signal quantification was performed using a Storm 840 PhosphorImager (Amersham Biosciences). The bands were normalized to the intensity of the $18 \mathrm{~S}$ band for each sample as measured by Quantity One 4.3.1 software on a Bio-Rad ChemiDoc (Bio-Rad).

$I L-8$ promoter reporter gene studies. The luciferase reporter gene constructs containing $135 \mathrm{bp}$ of the IL-8 $5^{\prime}$ flank has been previously described (46). Transient transfections of LS174T cells were performed using Lipofectamine 2000 (Invitrogen) and SV40 $\beta$-galactosidase as a transfection control. hRELM $\beta$ ( $1 \mu \mathrm{g} / \mathrm{ml}$; PeproTech) was added to the culture medium 24 hours after transfection. Forty-eight hours later, the cells were lysed and assayed for luciferase (Luciferase Assay System; Promega) and $\beta$-galactosidase. Each sample was assayed in triplicate, with the results expressed as mean light units per unit of $\beta$-galactosidase activity.

DSS-induced colitis. Eight male wild-type and RELM $\beta^{-/-}$littermate mice of 10 weeks age and weighing 23-28 g were fed 4\% DSS for 7 days (MP Biomedicals Inc.; molecular mass $36-50 \mathrm{kDa}$, dissolved in drinking water) 
as previously described (17). The mice had access to standard mice chow pellets. Weights, intestinal bleeding (hemoccults), and stool character were assessed on a daily basis by an investigator blinded to the genotype of the mice. All statistical analyses were performed using 2-tailed Student's $t$ test. $P$ values less than 0.05 were considered significant. The DSS was discontinued in the drinking water on day 8 of the study, and the survival of the mice was determined over the course of an additional 7 days. In a second experiment, wild-type and RELM $\beta^{-/-}$mice treated in an identical fashion were euthanized on day 7 for harvesting of colonic tissue to be analyzed by immunohistochemistry as described above.

The RELM $\beta$ enema add-back experiment utilized 16 male RELM $\beta^{-/-}$ mice, which were 20 weeks of age and weighed 24-33 g. Enemas were given twice daily at 12-hour intervals using an 18 French angiocatheter inserted $2 \mathrm{~cm}$ proximal to the anal verge in a volume of $200 \mu \mathrm{l}$. Mice were held upside down for 30 seconds after enema administration. Eight mice were given murine recombinant RELM $\beta$ (PeproTech) at a concentration of $2 \mu \mathrm{g} / \mathrm{ml}$ in PBS, and 8 mice were given enemas containing only $1 \times$ PBS. After the first day of enema administration, all mice were fed $4 \%$ DSS dissolved in drinking water as described above.

Electrophysiology measurements of epithelial barrier function. Mice were euthanized via $\mathrm{CO}_{2}$ asphyxiation after administration of $4 \%$ DSS for 2.5 days. Colonic tissue was then resected and mounted in an Üssing chamber for measurements of TER, an indicator of barrier function, and short-circuit current (Isc). Full-thickness, unstripped mucosa was bathed on both mucosal and serosal surfaces with $5 \mathrm{ml}$ of oxygenated $\left(95 \% \mathrm{O}_{2} / 5 \% \mathrm{CO}_{2}\right)$ Ringer solution containing (in mM): $\mathrm{NaCl} 109.8, \mathrm{KCl} 5.3, \mathrm{CaCl}_{2} 1.2, \mathrm{MgCl}_{2}$ 1.2, $\mathrm{NaHCO}_{3} 25, \mathrm{Na}_{2} \mathrm{HPO}_{4} 2.4, \mathrm{NaH}_{2} \mathrm{PO}_{4}$ 0.4. Additionally, the serosal bathing solution contained $10 \mathrm{mM}$ glucose, which was osmotically balanced by $10 \mathrm{mM}$ mannitol on the mucosal side. Bathing solutions were circulated in water-jacketed reservoirs and maintained at $37^{\circ} \mathrm{C}$.

Stimulation of thioglycolate-isolated macrophages with mRELM $\beta$. Peritoneal macrophages were harvested 3 days after injection of $10 \%$ Brewer thioglycolate (BD) by peritoneal lavage with PBS and plated in 24-well plates using 10\% FBS/DMEM. After 4 hours, adherent cells were washed twice with DMEM and thereafter kept in macrophage serum-free medium (Invitrogen) for further treatment. Supernatants were analyzed for the expression of 22 different cytokines after a 48-hour treatment interval with either recombinant murine RELM $\beta$ or human resistin protein $(1 \mu \mathrm{g} /$ $\mathrm{ml}$; PeproTech) using a Luminex multiplex protein assay system (catalog MCYTO-70K; Linco). Each measurement was performed in triplicate, with the results normalized to cellular protein content and expressed as picograms per milliliter.

Intraperitoneal administration of RELM $\beta$, cytospins, cell counts, and FACS analysis. Murine recombinant RELM $\beta$ ( $2 \mu \mathrm{g}$ in $100 \mu \mathrm{l}$ PBS; PeproTech) was injected i.p. into BALB/c mice, followed by peritoneal lavage after 1, 24, 48, and 72 hours as described previously (47). The vehicle control was spiked with 5 pg of LPS from E. coli (Sigma-Aldrich) to approximate the amount of endotoxin in the recombinant RELM $\beta$, less than $2.5 \mathrm{pg} / \mu \mathrm{g}$, measured by limulus assay. Total RNA was isolated from cells of the peritoneal lavage 1 hour after injection of RELM $\beta(0.5 \mu \mathrm{g}$ in $100 \mu \mathrm{l}$ PBS $)$, and TNF- $\alpha$ mRNA expression was determined by quantitative RT-PCR analysis (as described above). The morphological changes in macrophages, 24 hours after RELM $\beta$ administration, were assessed on cytospin preparations stained by Shandon Kwik-Diff (Thermo Electron Corp.), and total and differential cell counts were determined as described previously (47). Two hundred cells were counted for each of the cytospin slides under immersion oil, using a Nikon light microscope (at $\times 1,000$ magnification).

Peritoneal cells for analysis were harvested, 1 hour after injection of $\operatorname{RELM} \beta(0.5 \mu \mathrm{g}$ in $100 \mu \mathrm{l} \mathrm{PBS})$, by lavage with cold, sterile PBS and resuspended in staining buffer $(0.1 \% \mathrm{Na}$ azide, $2.5 \% \mathrm{FBS}$ in PBS) containing a predetermined optimal concentration of fluorochrome-conjugated antibodies or the corresponding isotype controls. The following antibodies were used for cell-surface staining: PE-conjugated anti-mouse F4/80, FITC-conjugated anti-mouse CD3e, APC-conjugated anti-mouse CD8a, PE-Cy5.5-conjugated anti-mouse/human CD45R (B220) (eBioscience), APC-conjugated anti-mouse CD4, PE-conjugated anti-mouse CD25 (BD Biosciences - Pharmingen).

For intracellular protein expression of TNF- $\alpha$ in macrophages, cells were washed and resuspended in Macrophage-SFM Medium (Invitrogen) containing L-glutamine, $10 \%$ FBS, penicillin, and streptomycin. Cells were cultured ex vivo in the presence of GolgiPlug (BD Biosciences - Pharmingen) protein transport inhibitor for 5 hours. Test samples were cultured without further stimulation. A pool of $5 \%$ of the cells from each mouse was stimulated with $0.5 \mu \mathrm{g}$ LPS and used as positive control. For analysis by flow cytometry, approximately $1 \times 10^{6}$ cells were incubated for 15 minutes with $1 \mu \mathrm{g}$ Fc Block (BD Biosciences - Pharmingen) followed by a 30-minute incubation with PE-conjugated anti-mouse F4/80 antibody at $4{ }^{\circ} \mathrm{C}$. Cells were then fixed and permeabilized using a Cytofix/Cytoperm kit (BD Biosciences - Pharmingen) and stained with APC-conjugated rat anti-mouse TNF- $\alpha$ antibody (BD Biosciences - Pharmingen). Background fluorescence was less than $0.5 \%$ after incubation with Ig isotype controls. Cells were analyzed on a FACSCalibur flow cytometer, and data were analyzed using CellQuest software version 5.2.1 (BD).

\section{Acknowledgments}

This work was supported by NIH grants AI39368 (to G.D. Wu), AI055593 (to A. Haczku), DK49210 (to M.A. Lazar), DK50694 (to G. Hecht), and DK57880 (to F. Cominelli and S.M. Cohn) and by the Molecular Biology and Morphology Cores of the NIH/NIDDK Center grants DK50306 and DK56703. T.M.H. Wong is supported by NIH grant DK07066. S.L. Barnes is supported by NIH grant DK06475 and by a United Negro College Fund/Merck Postdoctoral Science Research Fellowship. The authors also acknowledge the technical assistance of Xiaoming Wen in the development of the RELM $\beta$ targeting vector as well as Drew Weissman, Ekateryna Kryts$\mathrm{ka}$, and Laszlo Hortobagyi for their assistance in the FACS analysis.

Received for publication February 6, 2006, and accepted in revised form August 15, 2006.

Address correspondence to: Gary D. Wu, Suite 600 Clinical Research Building, 415 Curie Blvd., University of Pennsylvania School of Medicine, Philadelphia, Pennsylvania 19104, USA. Phone: (215) 898-0158; Fax: (215) 573-2024; E-mail: gdwu@ mail.med.upenn.edu.

Laila D. McVay and Sue A. Keilbaugh contributed equally to this work.
1. Steppan, C.M., et al. 2001. A family of tissue-specific resistin-like molecules. Proc. Natl. Acad. Sci. U. S. A. 98:502-506

2. Steppan, C.M., and Lazar, M.A. 2004. The current biology of resistin. J. Intern. Med. 255:439-447.

3. Bokarewa, M., Nagaev, I., Dahlberg, L., Smith, U., and Tarkowski, A. 2005. Resistin, an adipokine with potent proinflammatory properties. J. Immunol. 174:5789-5795.

4. Silswal, N., et al. 2005. Human resistin stimulates the pro-inflammatory cytokines TNF-alpha and IL-12 in macrophages by NF-kappaB-dependent pathway.
Biochem. Biophys. Res. Commun. 334:1092-1101.

5. Karmiris, K., et al. 2006. Circulating levels of leptin, adiponectin, resistin, and ghrelin in inflammatory bowel disease. Inflamm. Bowel Dis. 12:100-105.

6. He, W., et al. 2003. Bacterial colonization leads to the colonic secretion of RELMbeta/FIZZ2, a 
novel goblet cell-specific protein. Gastroenterology. 125:1388-1397.

7. Artis, D., et al. 2004. RELMbeta/FIZZ2 is a goblet cell-specific immune-effector molecule in the gastrointestinal tract. Proc. Natl. Acad. Sci. U. S. A 101:13596-13600.

8. Wang, M.L., et al. 2004. Regulation of RELM/ FIZZ isoform expression by $\mathrm{Cdx} 2$ in response to innate and adaptive immune stimulation in the intestine. Am. J. Physiol. Gastrointest. Liver Physiol. 288:G1074-G1083.

9. Sartor, R.B. 1997. The influence of normal microbial flora on the development of chronic mucosal inflammation. Res. Immunol. 148:567-576.

10. Elson, C.O. 1999. Experimental models of intestinal inflammation: new insights into mechanisms of mucosal homeostasis. In Mucosal immunology. P.L. Ogra et al., editors. Academic Press. San Diego, California, USA. 1007-1024.

11. Podolsky, D.K. 2002. Inflammatory bowel disease. N. Engl. J. Med. 347:417-429.

12. Uhlig, H.H., and Powrie, F. 2003. Dendritic cells and the intestinal bacterial flora: a role for localized mucosal immune responses. J. Clin. Invest. 112:648-651. doi:10.1172/JCI200319545.

13. Isaacs, K.L., and Sartor, R.B. 2004. Treatment of inflammatory bowel disease with antibiotics. Gas troenterol. Clin. North Am. 33:335-345.

14. Ogura, Y., et al. 2001. A frameshift mutation in NOD2 associated with susceptibility to Crohn's disease. Nature. 411:603-606.

15. Hugot, J.P., et al. 2001. Association of NOD2 leucine-rich repeat variants with susceptibility to Crohn's disease. Nature. 411:599-603.

16. Itoh, H., Beck, P.L., Inoue, N., Xavier, R., and Podolsky, D.K. 1999. A paradoxical reduction in susceptibility to colonic injury upon targeted transgenic ablation of goblet cells. J. Clin. Invest. 104:1539-1547.

17. Okayasu, I., et al. 1990. A novel method in the induction of reliable experimental acute and chronic ulcerative colitis in mice. Gastroenterology. 98:694-702.

18. Cooper, H.S., Murthy, S.N., Shah, R.S., and Sedergran, D.J. 1993. Clinicopathologic study of dextran sulfate sodium experimental murine colitis. Lab. Invest. 69:238-249.

19. Targan, S.R., et al. 1997. A short-term study of chimeric monoclonal antibody cA2 to tumor necrosis factor alpha for Crohn's disease. Crohn's Disease cA2 Study Group. N. Engl. J. Med. 337:1029-1035.

20. Myers, K.J., et al. 2003. Antisense oligonucleotide blockade of tumor necrosis factor-alpha in two murine models of colitis. J. Pharmacol. Exp. Ther. 304:411-424

21. Renigunta, A., et al. 2006. Human RELMbeta is a mitogenic factor in lung cells and induced in hypoxia. FEBS Lett. 580:900-903.

22. Strober, W., Fuss, I.J., and Blumberg, R.S. 2002. The immunology of mucosal models of inflammation. Annu. Rev. Immunol. 20:495-549.

23. Hollander, D., et al. 1986. Increased intestinal permeability in patients with Crohn's disease and their relatives. A possible etiologic factor. Ann. Intern. Med. 105:883-885.

24. Yoshihara, K., Yajima, T., Kubo, C., and Yoshikai, Y. 2006. Role of interleukin 15 in colitis induced by dextran sulphate sodium in mice. Gut. 55:334-341.

25. Bamias, G., et al. 2005. Proinflammatory effects of TH2 cytokines in a murine model of chronic small intestinal inflammation. Gastroenterology. 128:654-666.

26. Norkina, O., Burnett, T.G., and De Lisle, R.C. 2004. Bacterial overgrowth in the cystic fibrosis transmembrane conductance regulator null mouse small intestine. Infect. Immun. 72:6040-6049.

27. Rath, H.C., et al. 2001. Different subsets of enteric bacteria induce and perpetuate experimental colitis in rats and mice. Infect. Immun. 69:2277-2285.

28. Dieleman, L.A., et al. 1994. Dextran sulfate sodiuminduced colitis occurs in severe combined immunodeficient mice. Gastroenterology. 107:1643-1652.

29. Tessner, T.G., Cohn, S.M., Schloemann, S., and Stenson, W.F. 1998. Prostaglandins prevent decreased epithelial cell proliferation associated with dextran sodium sulfate injury in mice. Gastroenterology. 115:874-882.

30. Kitajima, S., Takuma, S., and Morimoto, M. 1999. Changes in colonic mucosal permeability in mouse colitis induced with dextran sulfate sodium. Exp. Anim. 48:137-143.

31. Goetz, F.W., Planas, J.V., and MacKenzie, S. 2004. Tumor necrosis factors. Dev. Comp. Immunol. 28:487-497.

32. Steppan, C.M., et al. 2001. The hormone resistin links obesity to diabetes. Nature. 409:307-312.

33. Rajala, M.W., Obici, S., Scherer, P.E., and Rossetti, L. 2003. Adipose-derived resistin and gut-derived resistin-like molecule- $\beta$ selectively impair insulin action on glucose production. J. Clin. Invest. 111:225-230. doi:10.1172/JCI200316521.

34. Kushiyama, A., et al. 2005. Resistin-like molecule beta activates MAPKs, suppresses insulin signaling in hepatocytes, and induces diabetes, hyperlipid- emia, and fatty liver in transgenic mice on a high fat diet. J. Biol. Chem. 280:42016-42025.

35. Wellen, K.E., and Hotamisligil, G.S. 2005. Inflammation, stress, and diabetes. J. Clin. Invest. 115:1111-1119. doi:10.1172/JCI200525102.

36. Hotamisligil, G.S., et al. 1996. IRS-1-mediated inhibition of insulin receptor tyrosine kinase activity in TNF-alpha- and obesity-induced insulin resistance. Science. 271:665-668.

37. Uysal, K.T., Wiesbrock, S.M., Marino, M.W., and Hotamisligil, G.S. 1997. Protection from obesityinduced insulin resistance in mice lacking TNFalpha function. Nature. 389:610-614

38. Marini, M., et al. 2003. TNF-alpha neutralization ameliorates the severity of murine Crohn's-like ileitis by abrogation of intestinal epithelial cell apoptosis. Proc. Natl. Acad. Sci. U. S. A. 100:8366-8371.

39. Bamias, G., et al. 2002. Down-regulation of intestinal lymphocyte activation and Th1 cytokine production by antibiotic therapy in a murine model of Crohn's disease. J. Immunol. 169:5308-5314.

40. Mashimo, H., Wu, D.C., Podolsky, D.K., and Fishman, M.C. 1996. Impaired defense of intestinal mucosa in mice lacking intestinal trefoil factor. Science. 274:262-265.

41. Sonnenburg, J.L., Angenent, L.T., and Gordon, J.I. 2004. Getting a grip on things: how do communities of bacterial symbionts become established in our intestine? Nat. Immunol. 5:569-573.

42. Halm, D.R., and Halm, S.T. 2000. Secretagogue response of goblet cells and columnar cells in human colonic crypts. Am. J. Physiol. Cell Physiol. 278:C212-C233.

43. Shapiro, L., and Scherer, P.E. 1998. The crystal structure of a complement-1q family protein suggests an evolutionary link to tumor necrosis factor. Curr. Biol. 8:335-338.

44. Patel, S.D., Rajala, M.W., Rossetti, L., Scherer, P.E., and Shapiro, L. 2004. Disulfide-dependent multimeric assembly of resistin family hormones. Science. 304:1154-1158.

45. Silberg, D.G., et al. 2002. Cdx2 ectopic expression induces gastric intestinal metaplasia in transgenic mice. Gastroenterology. 122:689-696.

46. Wu, G.D., Lai, E.J., Huang, N., and Wen, X. 1997. Oct-1 and CCAAT/enhancer-binding protein (C/EBP) bind to overlapping elements within the interleukin-8 promoter. The role of Oct-1 as a transcriptional repressor. J. Biol. Chem. 272:2396-2403.

47. Louahed, J., et al. 2001. Interleukin 9 promotes influx and local maturation of eosinophils. Blood. 97:1035-1042. 